\title{
Singapore Gp Fee Survey 20 I3: A Comparison With Past Surveys
}

Dr Andrew Epaphroditus Tay Swee Kwang, Dr Choo Kay Wee, A/Prof Gerald Koh Choon Huat

\begin{abstract}
Introduction: The rising cost of healthcare in Singapore has resulted in calls for greater price transparency. Similar to the GP (General Practitioner's) Fee Surveys done in 1996 and 2006, we undertook another one in 2013 to investigate the change in GP fees and GP operating costs over the years.
\end{abstract}

Methods: The 2013 GP Fee Survey involved 992 GPs and solo clinic practitioners. Results from the 2013 GP Fee Survey were compared against the 1996 and 2006 GP Fee Surveys. The Compound Annual Growth Rate (CAGR) was used to reflect the change in price data over the years and compared against the CAGR of the Consumer Price Index (CPI) and CPI-Health over the same periods.

Results: I I 3 participants (I I.5\%) responded. Between 1996 and 2013, the CAGR for CPI was I.84 percent and CPI-Health was 2.97 percent. In comparison, the CAGR for the median patient fee was 3.12 percent; staff salary was 1.95 percent; property cost was 2.47 percent; and total monthly practice cost was 9.21 percent.

Conclusion: Between 1996 and 2013, the rise in patients' fees matched the rise in CPI-Health but the rise in practice cost outpaced CPI-Health by more than threefold. However, the low response rate limits the generalisability of the data.

\section{Keywords:}

GP Fees; Healthcare Cost Inflation;

SFP20I7; 43(1): 42-5I

\section{INTRODUCTION}

Nobel Prize winner for economics, Kenneth J Arrow, ${ }^{1}$ described healthcare economics as an example of market failure. ${ }^{2}$ Information asymmetry between the supplier (medical professional) and the consumer (patients) places the medical

\section{ANDREW EPAPHRODITUS TAY SWEE KWANG}

Senior Resident, Family Physician

Preventive Medicine Residency, NUHS

\section{CHOO KAY WEE}

Family Physician

A Life Clinic Pte Ltd

\section{GERALD KOH CHOON HUAT}

Associate Professor and Director of Medical Undergraduate Education, Saw Swee Hock School of Public Health

And Yong Loo Lin School of Medicine professional in a privileged position to negotiate in a manner that could potentially undermine the patient's interest. ${ }^{2-5}$ Cognisant of this, the Guidelines on Fees (GOF) was promulgated in 1987 by the Singapore Medical Association (SMA) following complaints of overcharging by the public. The GOF establishment was aimed at safeguarding patients' interests and providing transparency of medical fees.

Since then, 2 surveys on GP fees were conducted in 1996 and 2006 respectively ${ }^{6,7}$ to provide timely and detailed information on the components of cost of practice in a general practice by the SMA. The results of the surveys were used to formulate the later editions of the GOF, before the GOF was voluntarily withdrawn by the SMA in $2007^{4,8}$ following the Competition Commission of Singapore's (CCS) decision that the GOF was anti-competitive, self-serving, and could potentially lead to the formation of a cartelist industry (price-fixing). ${ }^{8}$

Since the withdrawal of the GOF, reports of rising healthcare cost and overcharging ${ }^{9-11}$ have dominated the news, prompting the Government Parliamentary Committee (GPC) for Health to recommend annual surveys on professional fees and medical costs. ${ }^{11}$ Against this backdrop, this survey was conducted to provide an up-to-date information on GP fees and practice in Singapore where the majority (four-fifths) of primary care is provided by the private sector. ${ }^{6,7}$

\section{METHODOLOGY}

\section{Study Design}

A list of primary care clinics was obtained from the Ministry of Health $(\mathrm{MOH})$ website (http://mservices.moh.gov.sg/eservices /clinicSearch.do). The target groups of GPs were 1) "solo GPs", and 2) "single clinic operated by a GP with partners". Other forms of group practices were excluded from the survey since not all employed primary care doctors in group practices would be privy to the required information in the questionnaire. Clinic names suggestive of aesthetic practices, in-house clinics of business corporations, and clinics of learning institutions were also excluded from the survey as the mode of operation of the clinics would likely be different from that of the traditional GPs. In the end, 992 clinics were identified.

A self-administered questionnaire was designed. To facilitate the answering of the anonymised questionnaire, the participants were asked to select options within various questions that best described their practices rather than provide open-ended answers. Hard copies of the questionnaire and the participant information sheet were mailed to the clinics with a pre-paid self-addressed envelope in May 2013.

As the survey was anonymous, no personal identifier was collected. Participation in the survey was entirely voluntary and no incentive was offered to the participants. To avoid the possibility of double counting, reminder mails with duplicate questionnaire were not sent to the participants. The study was 
reviewed and approved by the National University of Singapore (NUS) Institutional Review Board (IRB).

For cost of practice, we collected data such as monthly non-doctor staff and doctor salary, cost of medicines, operating cost, and property cost. We also collected data such as average number of patients seen monthly, fee charged per consultation, and total monthly GP clinic revenue.

\section{Computations}

Where open-ended numerical data was obtained (such as age and consultation fees), the actual figure quoted by the respondents was used during analyses.

Where free-text data was given in the form of a range (e.g. \$20 to $\$ 30)$, the midpoint of the range will be used for analyses.

Where pre-coded questions were presented with a range of numerical data in the form of an ordinal scale (e.g. most cost data in our questionnaire), the midpoint of the range was used for computation.

To calculate total monthly practice cost, we summed the reported non-doctor staff salary, cost of medicines, operating cost, and property cost on an individual clinic level. To calculate average fee paid by patient, we divided total monthly GP clinic revenue by number of patients seen monthly and termed this "calculated fee per patient" on an individual clinic level. It is important to note that the consultation fee charged is often a sub-item of the "calculated fee per patient" as the latter also includes medicine cost and clinic overheads. These computations were similar to the method of computation in the 1996 and 2006 GP Fee Surveys.

Where categorical variables were compared between groups, the Fisher Exact test was used to assess the statistical significance of the effect measure.

\section{Comparisons With Past Surveys and Consumer Price Index (CPI) using Compound Annual Growth Rate (CAGR)}

The results of this survey were compared against the results of the past GP Fee Surveys (1996 and 2006) of Singapore. The compound annual growth rate $^{12}$ (CAGR) was used to reflect the changes in prices over time. The resultant CAGR was compared against the CAGR of the Singapore Consumer Price Index (CPI), and Consumer Price Index for Health (CPI-Health). ${ }^{13,14}$

The CPI measures price changes in a fixed basket of consumption goods and services commonly purchased by households over time ${ }^{15}$ and is a measure of consumer price inflation. CPI-Health, similar to the CPI, tracks the price changes of healthcare expenditure among households. CPI-Health is, thus, a measure of healthcare inflation.

The CAGR reflects the year-on-year percentage growth rate of a price or an investment over a period of time. ${ }^{12}$ The formula is illustrated in Figure 1. As an illustration, Singapore's CPI-Health grew from 69.22 in 1996 to 113.17 in 2013 with different rates annually (ranging from $0.44 \%$ to $5.96 \%) .{ }^{14}$ The CAGR for the CPI-Health over these 17 years was 2.97 percent. This means that the CPI-Health grew at a smoothed annualised rate of 2.97 percent during these 17 years.

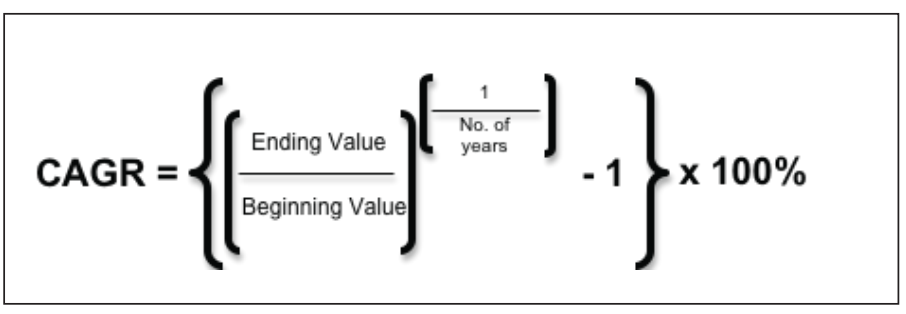

Figure 1 : Compound Annual Growth Rate (CAGR) Formula

\section{Median and Mean}

Median and mean are common measures of the central tendency. As described in the previous GP Fee Surveys, ${ }^{6,7}$ the mean is commonly understood and allows for further analysis. However, the use of mean can be influenced by extreme values and skewed distributions. The median, on the other hand, is not affected by extreme values and skewed distribution. As cost and financial data are often skewed, we reported medians for such data and included the means where appropriate (e.g. to allow comparisons of our result with previous GP Fee Surveys).

\section{Older GP Participants versus Younger GP Participants}

The 25th percentile age-value would be used as the cut-off to compare the operational plight between the relatively younger GPs (aged 25th percentile age-value and below) and the relatively older GPs (aged more than 25th percentile age-value).

\section{RESULTS}

\section{Response Rate}

Out of the 992 clinics that were sent the survey questionnaires, 6 envelopes were returned because the addresses were no longer valid and 113 GPs responded, giving a response rate of 11.5 percent.

\section{Profile of GPs and Clinics}

The mean age of the GPs was 52.6 (range: 33 to 80 year old) (Table 1). The mean years of operation was 20 (median: $16.5)$, and ranged from 1 to 60 years. Eighty (72.1\%) clinics were located in Housing Development Board (HDB estate), $13(11.7 \%)$ in shop houses, $11(9.9 \%)$ in shopping malls, 3 $(2.7 \%)$ in office buildings, and $4(3.60 \%)$ in other locations. Eighty-nine (78.8\%) GPs operated as solo GPs while the rest of the clinics operated as a single clinic with partners.

\section{Mode of Operation}

Seventy (62.5\%) GPs operated more than 2 sessions each weekday while $42(37.5 \%)$ operated 2 sessions or less each weekday (Table 1). Approximately equal proportion of GPs worked 44 hours or less per week $(50.5 \%)$ while 4 GPs did not indicate the number of hours they worked per week. Fifty-nine (52.2\%) GPs indicated that they employed other doctors to maintain the function of the clinic while 54 $(47.8 \%)$ did not employ other doctors. 
Out of 113 respondents, 7 GPs (6.2\%) offered aesthetic medicine in their clinic.

Table 1: Profile of GPs and Clinics

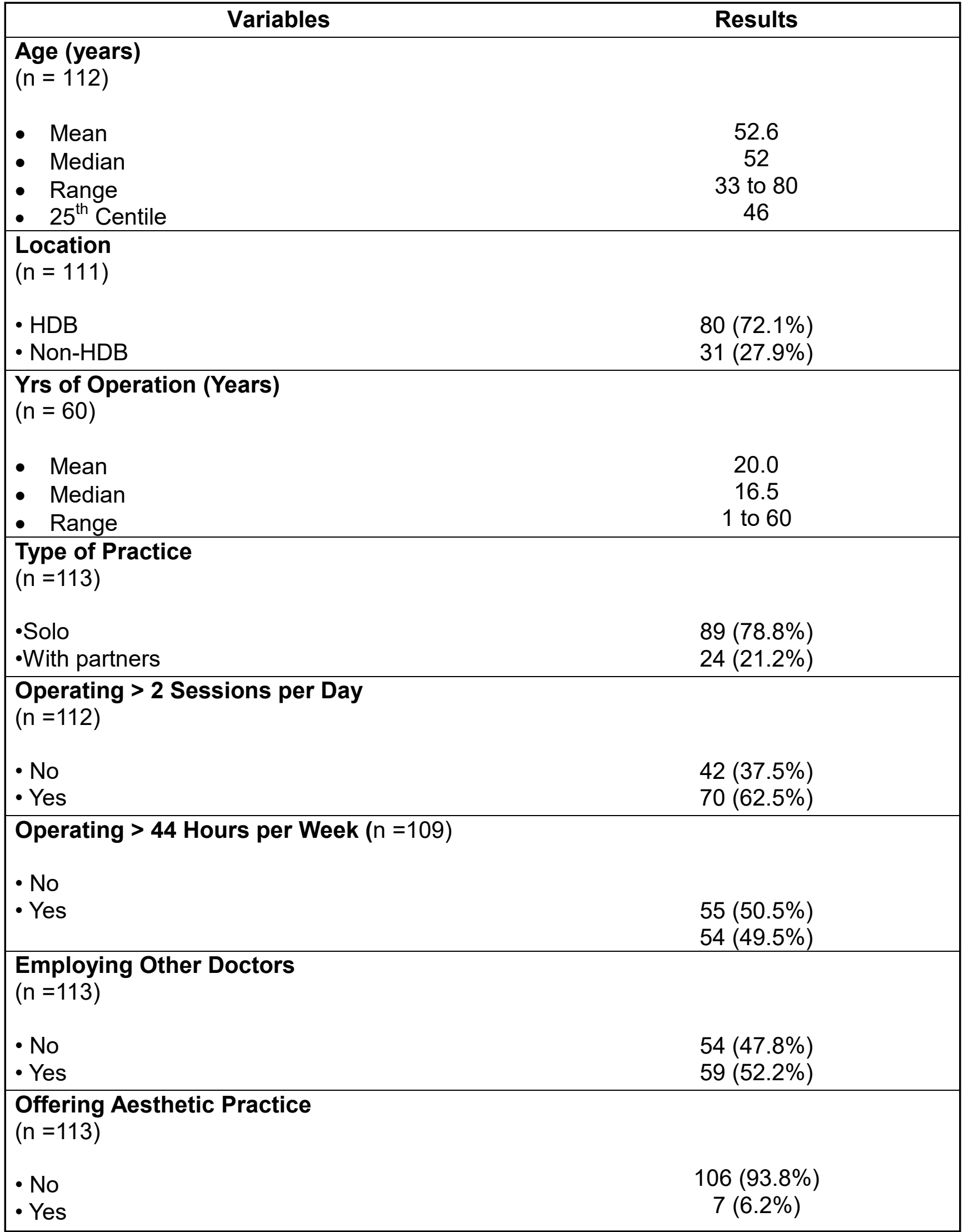

( $n=$ No. of responses available)

\section{Cost of Practice}

The median monthly non-doctor staff salary was $\$ 6,000$ (range: $\$ 4,000$ to $\$ 30,000)$; median monthly cost of medicine was $\$ 12,500$ (range: $\$ 5,000$ to $\$ 57,500$ ); median monthly operating cost was $\$ 4,000$ (range $\$ 4,000$ to $\$ 65,000$ ); median monthly property cost was $\$ 5,000$ (range: $\$ 2,000$ to $\$ 15,000$ ); 
while the median monthly doctor salary was $\$ 10,000$ (range: $\$ 0$ to $\$ 42,000$ ) (Table 2 ). The median total monthly practice cost (not including monthly doctor's salary) was $\$ 31,000$ (range: $\$ 15,000$ to $\$ 92,500$ ); median number of patients attending the GP clinic monthly was 1,500 (range: 600 to 3300). By dividing the total monthly practice cost by the number of patients for each GP per month, the median practice cost was $\$ 28.31$ per patient.
Consultation and Patient Fee and Clinic Revenue The mean consultation fee charged was $\$ 22.73$ while the median was $\$ 20$ (range: $\$ 0$ to $\$ 100$ ) (Table 3). The median monthly revenue was $\$ 52,500$ (range $\$ 15,000$ to $\$ 172,500$ ).

By dividing the monthly clinic revenue by the number of patients attended by each GP per month, the mean amount of fees payable by each patient was $\$ 39.64$ while the median was

Table 2: Cost of Practice

\begin{tabular}{|c|c|}
\hline Description & $\begin{array}{l}\{\text { Mean }\} \\
\text { Median } \\
\text { Range }\end{array}$ \\
\hline $\begin{array}{l}\text { Non-Doctor Staff Salary (Monthly) (a) } \\
(n=108)\end{array}$ & $\begin{array}{c}\{\$ 7,185\} \\
\$ 6,000 \\
4,000 \text { to } \$ 30,000\end{array}$ \\
\hline $\begin{array}{l}\text { Monthly Cost of Medicine (b) } \\
(n=106)\end{array}$ & $\begin{array}{c}\{\$ 15,873\} \\
\$ 12,500 \\
\$ 5,000 \text { to } \$ 57,500\end{array}$ \\
\hline $\begin{array}{l}\text { Monthly Operating Cost (c) } \\
(\mathrm{n}=109)\end{array}$ & $\begin{array}{c}\{\$ 6,541\} \\
\$ 4,000 \\
\$ 4,000 \text { to } \$ 65,000\end{array}$ \\
\hline $\begin{array}{l}\text { Property (Monthly) (d) } \\
(n=108)\end{array}$ & $\begin{array}{c}\{\$ 5,620\} \\
\$ 5,000 \\
\$ 2,000 \text { to } \$ 15,000\end{array}$ \\
\hline $\begin{array}{l}\text { Monthly Doctor Salary } \\
(\mathrm{n}=103)\end{array}$ & $\begin{array}{c}\{\$ 10,078\} \\
\$ 10,000 \\
\$ 0 \text { to } \$ 42,000\end{array}$ \\
\hline $\begin{array}{l}\text { Total Monthly Practice Cost (e) } \\
{[(a)+(b)+(c)+(d)]} \\
(\mathrm{n}=95)\end{array}$ & $\begin{array}{c}\{\$ 33,985\} \\
\$ 31,000 \\
\$ 15,000 \text { to } \$ 92,500\end{array}$ \\
\hline $\begin{array}{l}\text { Number of Patients Seen Monthly (f) } \\
(n=107)\end{array}$ & $\begin{array}{c}\{1,293\} \\
1,500 \\
600 \text { to } 3,300\end{array}$ \\
\hline $\begin{array}{l}\text { Practice Cost Per Patient } \\
{[(\mathrm{e}) \div(\mathrm{f})]} \\
(\mathrm{n}=92)\end{array}$ & $\begin{array}{c}\{\$ 28.31\} \\
\$ 25 \\
\$ 10.71 \text { to } \$ 62.78\end{array}$ \\
\hline
\end{tabular}


$\$ 35$ (range: $\$ 16.67$ to $\$ 141.67$ ). The fees payable by each patient ("patient fee") theoretically included the consultation fee, and the medication and clinical investigation charges.

The profit for each GP was computed by subtracting monthly total cost from the monthly clinic revenue. This consequently gave a median profit of $\$ 15,000$ (range $-\$ 21,000$ to $\$ 95,000$ ) per month per GP.

\section{Comparisons with Past GP Fee Surveys}

Table 4 summarises the results of this survey together with the available results from the 1996 and 2006 GP Fee Surveys. In general, the number of patients seen monthly, practice costs and calculated fee per patient have increased from 1996 to 2013.

The corresponding CAGRs for the variables in Table 4 for each pair of time points of the 3 GP Fee Surveys [(i.e. 1996 to 2006 (10 years), 2006 to 2013 (7 years) and 1996 to 2013 (17 years)] are detailed in Table 5. Based on national data, the CAGR of CPI-Health (healthcare inflation) at 2.97 percent surpassed CPI (general inflation) at 1.84 percent, between 1996 and 2013, indicating that the inflation rate for healthcare costs generally surpassed general inflation. ${ }^{13,14}$ The highest CAGRs for CPI and CPI-Health occurred between 1996 and 2013 (1.84\% and $2.97 \%$ respectively). The CAGR for median total monthly practice cost was 8.97 percent from 1996 to 2006, 5.44 percent from 2006 to 2013, and 7.50 percent from 1996 to 2013. From 1996 to 2013, the CAGR for the median total monthly practice cost exceeded CPI by 4.1 times and CPI-Health by 2.5 times. In contrast, the CAGR of the median monthly revenue per patient (i.e. calculated fee per patient) was correspondingly lower at 3.07 percent from 1996 to 2006, 2.23 percent from 2006 to 2013 and 3.12 percent from 1996 to 2013. From 1996 to 2003, the CAGR of the median monthly calculated fee per patient only exceeded the CAGR for CPI by 1.7 times and matched the CAGR for CPI-Health.

Table 3: Consultation Charge, Clinic Revenue and Calculated Fee per Patient

\begin{tabular}{|c|c|}
\hline Description & $\begin{array}{l}\{\text { Mean\} } \\
\text { Median } \\
\text { Range }\end{array}$ \\
\hline $\begin{array}{l}\text { Consultation Charges } \\
(n=88)\end{array}$ & $\begin{array}{c}\{\$ 22.64\} \\
\$ 20 \\
\$ 0 \text { to } \$ 100\end{array}$ \\
\hline $\begin{array}{l}\text { Monthly Revenue (g) } \\
(\mathrm{n}=101)\end{array}$ & $\begin{array}{c}\{\$ 50,316\} \\
\$ 52,500 \\
\$ 15,000 \text { to } \$ 172,500\end{array}$ \\
\hline $\begin{array}{l}\text { Number of Patients Seen Monthly (f) } \\
(n=107)\end{array}$ & $\begin{array}{c}\{1293\} \\
1,500 \\
600 \text { to } 3,300\end{array}$ \\
\hline $\begin{array}{l}\text { Calculated Fee Per Patient } \\
{[(g) \div(f)]} \\
(n=99)\end{array}$ & $\begin{array}{c}\{\$ 39.64\} \\
\$ 35 \\
\$ 16.67 \text { to } \$ 141.67\end{array}$ \\
\hline $\begin{array}{l}\text { Total Monthly Profit } \\
{[(g)-(e)]^{*}} \\
(n=90)\end{array}$ & $\begin{array}{c}\{\$ 16,609\} \\
\$ 15,000 \\
-\$ 21,000 \text { to } \$ 95,000\end{array}$ \\
\hline
\end{tabular}

( $n=$ no. of responses available)

( ${ }^{*}$ Amount does not include monthly doctor's salary) 
Table 4: Cost Comparisons between 1996, 2006 and 2013 GP Fee Surveys

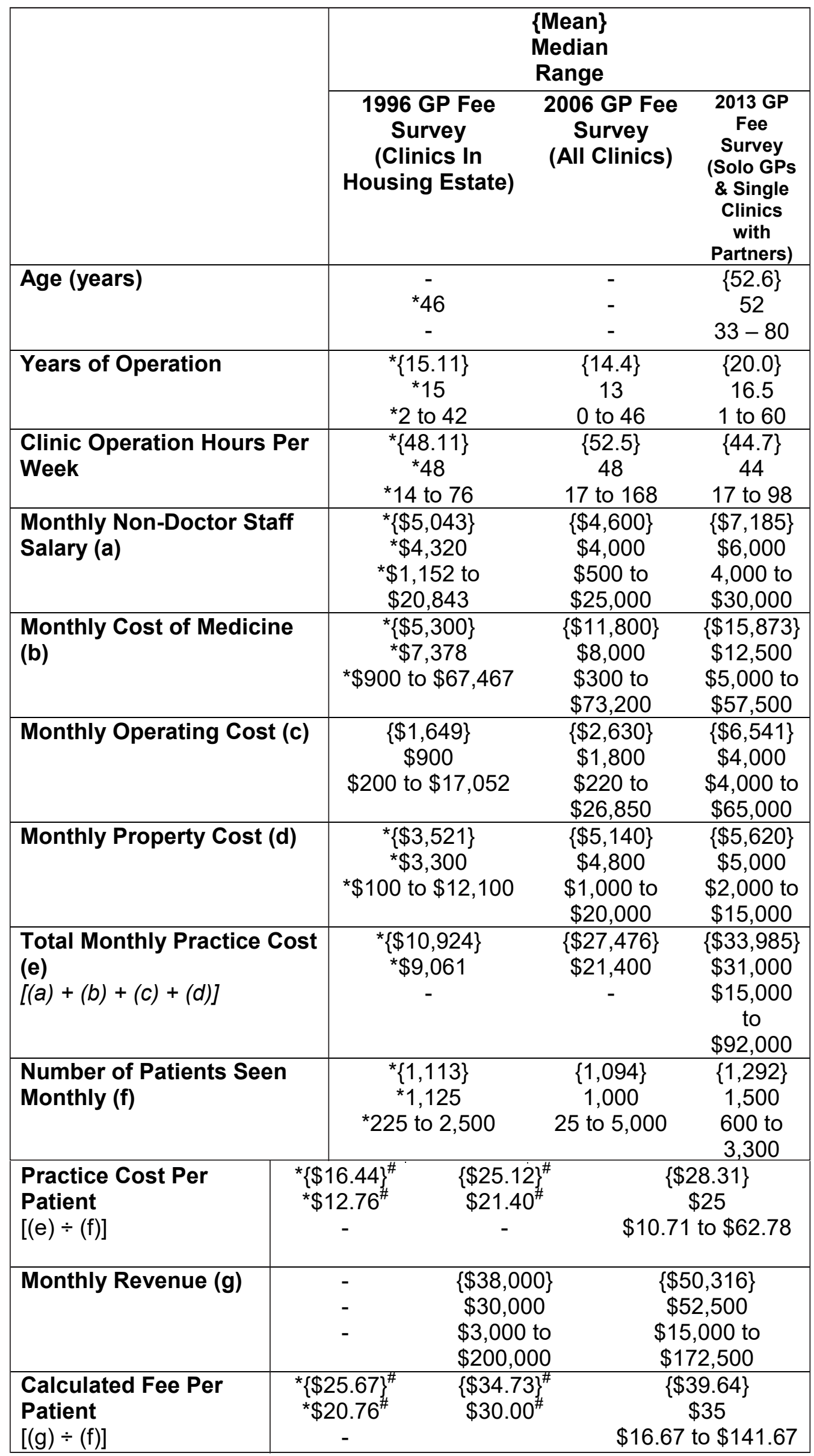

${ }^{*}$ Results only encompass Solo GPs in the 1996 Survey

\# Calculation was based on aggregate data 
Table 5: Compound Annual Growth Rate (CAGR) Comparisons Between 1996, 2006 and 2013 GP Fee Surveys

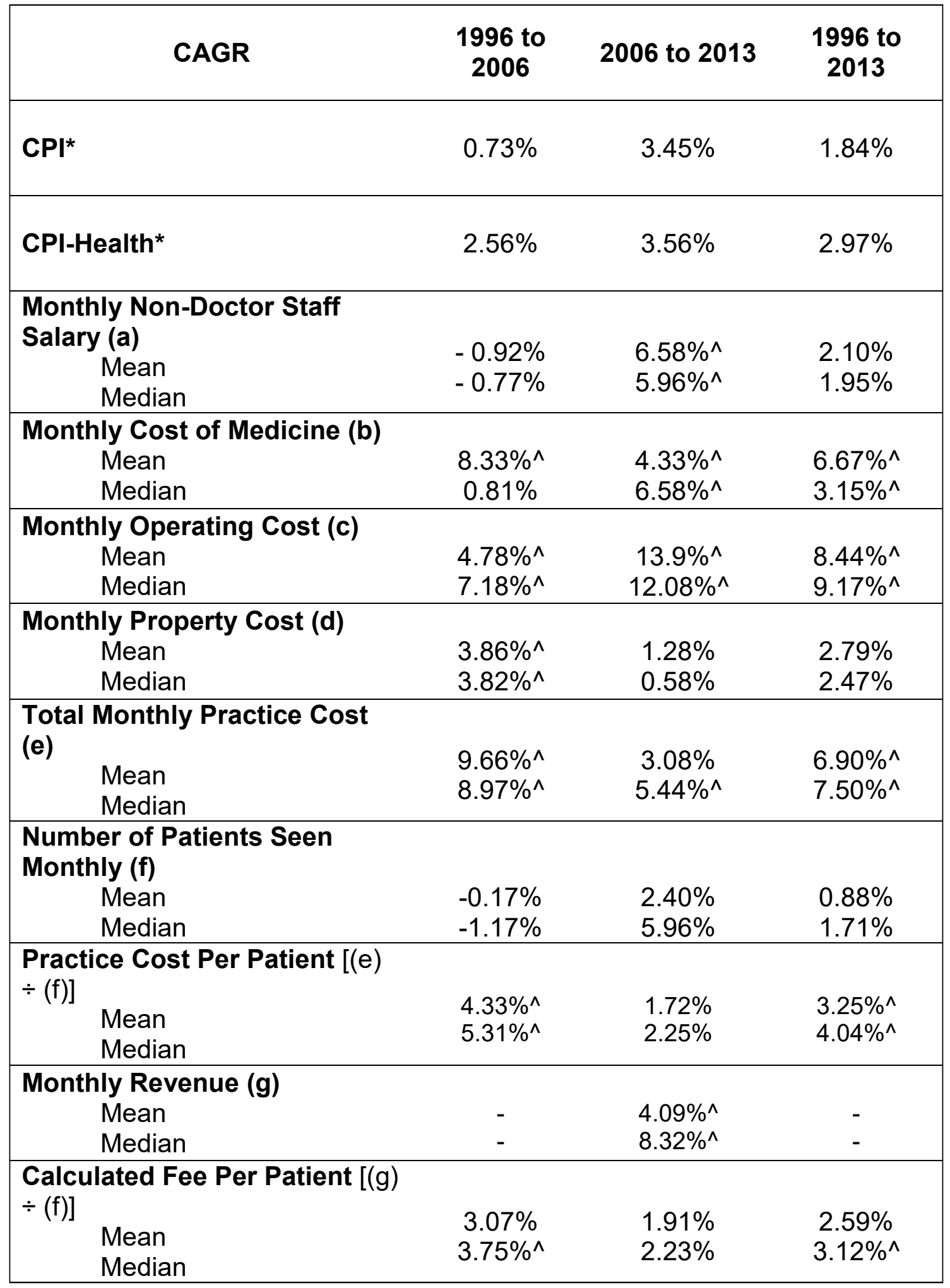

* Based on national data

${ }^{\wedge}$ Denotes item that outpaces both CPI and CPI-Health in the corresponding period. 


\section{Comparisons between Relatively Younger and Older GPs}

Age of 46 years (25th percentile) is the demarcation between the younger GPs (age 46 and younger) and the older GPs (older than 46 years). The comparisons in the operational conditions are summarised in Table 6.
While the increase in CAGR for median monthly practice cost outstripped the CPI-Health by 2.5 times, the CAGR for median calculated fee per patient matched the increases in CAGR in CPI-Health between 1996 and 2013. It seems that the GPs have been operating their practices under trying circumstances ${ }^{7}$ in the past two decades, with practice costs rising but needing to keep prices competitive and affordable for patients.

Table 6: Comparisons between Relatively Younger GPs and Older GPs

\begin{tabular}{lccc}
\hline & $\begin{array}{c}\text { Prevalence Rate } \\
\text { Ratio }\end{array}$ & $\begin{array}{c}\text { 95\% Confidence } \\
\text { Interval }\end{array}$ & *P-Value \\
\hline $\begin{array}{l}\text { Property cost } \\
\text { S\$6,000 or more } \\
\text { (Monthly) }\end{array}$ & 1.96 & $(1.11-3.46)$ & 0.031 \\
\hline $\begin{array}{l}\text { Operate more than } \\
\text { 2 sessions per } \\
\text { working day }\end{array}$ & 1.39 & $(1.05-1.83)$ & 0.049 \\
\hline $\begin{array}{l}\text { Work more than } \\
\text { 44 hours per week }\end{array}$ & 1.60 & $(1.10-2.32)$ & 0.033 \\
\hline $\begin{array}{l}\text { Practice type as } \\
\text { "Single Clinic } \\
\text { With Partners" }\end{array}$ & 2.89 & $(1.39-6.00)$ & 0.007 \\
\hline $\begin{array}{l}\text { Consultation } \\
\text { Charge more than } \\
\text { \$20 }\end{array}$ & 0.822 & $(0.45-1.51)$ & 0.63 \\
\hline
\end{tabular}

${ }^{*}$ Fisher Exact Test

In this study, Younger GPs are 1.96 times (95\% CI 1.11 to 3.46 ) more likely to incur monthly property cost $\$ 6,000$ or more, 1.39 times (95\% CI 1.05 to 1.83 ) more likely to operate more than 2 sessions per working day, 1.6 times (95\% CI 1.10 to 2.32 ) more likely to work more than 44 hours per week, and 2.89 times (95\% CI 1.39 to 6.00$)$ more likely to work with partners in operating the GP practice.

There was no statistically significant correlation in the consultation charges (Prevalence rate ratio 0.822 , 95\% CI 0.45 to 1.51 ) between the 2 groups.

\section{DISCUSSION}

Our study computed the rise in clinic operating cost over the past 17 years (1996 to 2013) and found a year-on-year increase in total monthly practice cost, contributed by external factors such as rising staff salaries, cost of drugs, and property cost. Such economic influences ultimately have a rippling contribution to the rise in CPI-Health.
It is estimated that at least two-thirds of primary care is provided by solo and small-group GPs. ${ }^{6,7}$ Solo GPs and single-clinic practices do not enjoy economies of scale and work with lean manpower compared to group practices, and thus are vulnerable to the external influences of rising operating costs while maintaining competitive pricings. In such a scenario, there exists the temptation for GPs to venture into non-traditional areas of GP work, such as aesthetic medicine, to supplement their income and keep the GP practices viable. ${ }^{7}$

The benefits of having financially viable and sustainable GP services and traditional primary care have been cited in many studies. ${ }^{7,17-20}$ The presence of primary care services has been associated with lower total all cause, stroke, cardiovascular and post-neonatal mortality. ${ }^{17-20}$ On the economic front, strong primary care services have been associated with lower costs to the healthcare system. ${ }^{21}$ Hence, it is necessary to ensure that the GP fraternity continues to provide good primary care services without the distraction of external economic pressures. This is especially important in Singapore where 80 percent of primary care is provided by the GP sector. 
Cognisant of rising healthcare cost, recent reforms to the Singapore healthcare system includes the enhancement of the Community Health Assist Scheme (CHAS) ${ }^{22}$ and the introduction of the Pioneer Generation Package (PGP). ${ }^{23}$ Central to these initiatives is the reduction of out-of-pocket costs for the patients during their medical visits to the participating GPs. While such measures improve the affordability of GPs for patients and incentivises patients to seek medical attention from GPs instead of the public primary care (i.e. polyclinics), they do not directly address the issues of rising clinic operating costs.

On this front (i.e. rising clinic operating cost), we found that the younger doctors (aged 46 and below) faced economic challenges of higher property cost and higher total operating cost than the older GPs. However, the younger GPs still had to charge competitively so as to remain competitive. Faced with such challenges, younger GPs would tend to operate the clinic practices with partners. This observation was named "generational inequity" by Dr Tan, a Council Member of the SMC. ${ }^{26}$ In his opinion published in The Straits Times (dated 5 September 2013, p. A35), he described the economic challenges that confronted younger doctors in the face of a high rate of inflation when compared to their older counterparts. The latter are able to operate their GP practices at a lower base, and therefore charge medical fees competitively. Our study is the only one that is able to crystallise this concept of "generational inequity" on a numerical basis.

\section{Study Limitations}

The low response rate $(11.5 \%)$ reduced the generalisability of the results to the GP practice at large. However, internationally, surveys involving GPs consistently have low response rates. ${ }^{24,25}$ Kaner et al summarised the reasons for GPs not being involved in surveys. They included busy work schedule, habitual binning of the questionnaires, increase in administration, and getting questionnaires lost in the midst of doing paperwork. ${ }^{24}$ Locally, the response rates for the 1996 and 2006 GP Fee Surveys were 50 percent and 24 percent respectively, despite engaging student volunteers to assist in manual data collection and having a widened GP pool that included multi-clinic group practices that were excluded in our study.

As with all self-administered surveys, recall bias is unavoidable. Nevertheless, this was reduced by conducting the survey in May 2013, one month after the deadline for business income submission to the Inland Revenue Authority of Singapore (IRAS) so as to facilitate recollection of the requested data.

The findings in this study cannot be directly extrapolated to clinics under large group practices. With the advantage of resource pooling and discounts from bulk purchases, the mode of operation and cost structure of multi-clinic group practices differ greatly from that of the solo GPs and single-practice GPs.

Similarly, primary care clinics with predominantly aesthetic services may operate differently as compared to traditional GP clinics. With costly aesthetic machine investments being factored into a clinic's operating cost, it is likely that the clinic operations and cost structure of primary care clinics with predominantly aesthetic services are different from the traditional GP clinics.
The different methodologies employed in the data collection and analyses of the 3 GP Fee Surveys ${ }^{6,7}$ limit the validity of the cost comparisons illustrated in this study. For example, the 1996 and the 2006 GP Fee Surveys collected absolute cost data for the calculation of the clinic operating costs and the patient fees, in contrast to the use of a range of cost data in the same categories in our 2013 GP Fee Survey. In addition, when computing total monthly practice cost and fee per patient, the 1996 and 2006 surveys used aggregate-level data whereas we used individual-level data in our 2013 survey. Nevertheless, sensitivity analysis using the 1996 and 2006 surveys' aggregate-level method of computing these indices on our 2013 data, the final values remain largely similar to the values obtained when we used individual level data. Lastly, the earlier GP Fee Surveys consisted of a heterogeneous group of GPs with different modes of operation, while this 2013 GP fee survey was limited to solo GPs and single-clinic practices. However, despite these limitations, the lack of data on GP clinic operations in Singapore restricts the alternative ways of assessing the changes in GP fees over the years.

\section{CONCLUSION}

Between 1996 and 2013, the rise in the patient fees matched the rise in CPI-Health, but the rise in total monthly practice cost outpaced CPI-Health by 2.5 times. It appears that GPs have been keeping their prices competitive and affordable for patients despite rising practice costs.

\section{REFERENCES}

I. Nobelprize.org. Kenneth J. Arrow - Facts [Internet]. Available from: http://www.nobelprize.org/nobel_prizes/economic-sciences/laureates/19 72/arrow-facts.html. [Accessed on 7 November 2016].

2. Haas-Wilson D. Arrow and the information market failure in health care: the changing content and sources of health care information. J

Health Polit Policy Law. 200 I;26:1031-44. [Retrieved 5 November 2013, from Project MUSE database].

3. Watts JJ, Segal L. Market failure, policy failure and other distortions in chronic disease markets. BMC Health Serv Res. 2009;9:102.

4. Vladeck BC, Rice T. Market failure and the failure of discourse: facing up to the power of sellers. Health Aff (Millwood). 2009;28:1305-I5. 5. Wong CY. Could SMA have not withdrawn the guidelines on fees (GOF)? [Internet]. SMA News. 2007;39:4-7. Available from: http://news.sma.org.sg/3904/Forum.pdf. [Accessed on 2I October 2013]. 6. Singh K, Goh LG, Sandhu K, Cheong PY. 1996 survey of housing estate practice costs and GP fees in Singapore. Singapore Med J. 1997;38:192-9.

7. Wong CY, Tan K, Foo G, Chua A, Lee YV, Wong TH, et al. 2006 Survey of GP Clinic Practice Costs in Singapore. SMA News. 2007;39:10-19.

8. Competition Commission Singapore 2010. Singapore Medical Association - Guidelines on Fees [Internet]. Available from: https://www.ccs.gov.sg/ /media/custom/ccs/files/public\%20register\%20an d\%20consultation/public\%20consultation\%20items/singapore\%20medical \%20association\%20\%20guidelines\%20on\%20fees/smasd\%2018\%20aug\%2 $02010 . a s h x$. [Accessed on 12 Nov 2016].

9. Singaporelaw.sg. Lim Mey Lee Susan v Singapore Medical Council [Internet]. Available from:

http://www.singaporelaw.sg/sglaw/laws-of-singapore/case-law/free-law/hi gh-court-judgments/ I 5283-lim-mey-lee-susan-v-singapore-medical-counc il-2013-sghc-I 22 [Accessed: I 2 Nov 2016]. 
10. Lim J. Reining in the healthcare inflation beast. TODAY, Jan. 7, 2013. [Internet]. Available at:

http://www.todayonline.com/commentary/reining-healthcare-inflation-be ast [Accessed I 2 Nov 2016]

II. The Government Parliamentary Committee for Health. GPC (Health) report on improving healthcare affordability for Singaporeans [Internet]. Available from: www.moh.gov.sg http://www.moh.gov.sg/content/moh_web/home/pressRoom/highlights/2 013/gpc--health--report-on-improving-healthcare-affordability-for-si.html. [Accessed on 28 October 20I3].

12. REUTERS. Compound Annual Growth Rate [Internet]. Available from:

http://glossary.reuters.com/index.php?title=Compound_Annual_Growth _Rate [Accessed on 3I October 20I3].

13. The Ministry of Health, Singapore. Consumer price indices (CPI) \& household healthcare expenditure [Internet]. Available from:

https://www.moh.gov.sg/content/moh_web/home/statistics/Health_Facts _Singapore/Consumer_Price_Indices_CPI_and_Household_healthcare_E xpenditure.html [Accessed I 2 Nov 2016]

14. Monetary Authority of Singapore. Goods \& services inflation calculator. Available from:

https://secure.mas.gov.sg/calculator/goodsandservices.aspx [Internet]. [Accessed on 2 August 2014].

I5. Department of Statistics Singapore. Statistics Singapore - FAQ on CPI [Internet]. Available from:

http://www.singstat.gov.sg/educational-corner/faq-on-CPI. [Accessed 12 Nov 2016]

16. Watson T. 2014 Global Medical Trends, Ist ed [Internet]. Available at:

http://www.towerswatson.com/en/Insights/lC-Types/Survey-Research-Re sults/20I4/05/20I4-global-medical-trends-survey-report. [Accessed on 13 August 2014].
17. Kruk ME, Porignon D, Rockers PC, Van Lerberghe W. The contribution of primary care to health and health systems in low- and middle-income countries: a critical review of major primary care initiatives. Soc Sci Med. 2010;70:904-II.

18. Macinko J, Starfield B, Shi L. The contribution of primary care systems to health outcomes within organization for economic cooperation and development (OECD) Countries, 1970-1998. Health Serv Res. 2003;38:83 I-65. doi: I0. I I I I/ /475-6773.00 I49.

19. Shi L, Starfield B, Kennedy B, Kawachi I. Income inequality, primary care, and health indicators. J Fam Pract. 1999;48:275-84.

20. Starfield B, Shi L, Macinko J. Contribution of primary care to health systems and health. Milbank Q. 2005;83:457-502.

2I. Starfield B, Shi L. Policy relevant determinants of health: an international perspective. Health Policy. 2002;60:20I-I8.

22. Ministry of Health. Community Health Assist Scheme | Ministry of Health. 2014 [Internet]. Available from:

http://www.moh.gov.sg/content/moh_web/home/costs_and_financing/sch emes_subsidies/Community_Health_Assist_Scheme.html. [Accessed on 14 August 2014].

23. The Ministry of Health Singapore. Pioneer Generation Package. [Internet]. Available from:

www.moh.gov.sg/content/moh_web/home/costs_and_financing/schemes _subsidies/pioneer-generation-package.html. [Accessed I2 Nov 2016]. 24. Kaner EF, Haighton CA, McAvoy BR. 'So much post, so busy with practice--so, no time!': a telephone survey of general practitioners' reasons for not participating in postal questionnaire surveys. $\mathrm{Br} J \mathrm{Gen}$ Pract. 1998;48: 1067-9.

25. Creavin ST, Creavin AL, Mallen CD.. Do GPs respond to postal questionnaire surveys? A comprehensive review of primary care literature. Fam Pract. 201 I;28:46I-7. doi: 10.1093/fampra/cmr00 I. 26. Tan CC. What fuels health-care costs? A view from the coalface. The Straits Times. 5 September 2013. 